This is a self-archived version of an original article. This version may differ from the original in pagination and typographic details.

Author(s): Kauppinen, Merja; Kiili, Carita; Coiro, Julie

Title: Experiences in Digital Video Composition as Sources of Self-Efficacy Toward Technology Use

Year: 2018

Version: Published version

Copyright: (c) 2018, IGI Global.

Rights: In Copyright

Rights url: http://rightsstatements.org/page//nC/1.0/?language=en

Please cite the original version:

Kauppinen, M., Kiili, C., \& Coiro, J. (2018). Experiences in Digital Video Composition as Sources of Self-Efficacy Toward Technology Use. International Journal of Smart Education and Urban Society, 9(1). https://doi.org/10.4018/IJSEUS.2018010101 


\title{
Experiences in Digital Video Composition as Sources of Self- Efficacy Toward Technology Use
}

\author{
Merja Kauppinen, University of Jyväskylä, Jyväskylä, Finland \\ Carita Kiili, University of Oslo, Oslo, Norway \\ Julie Coiro, University of Rhode Island, Kingston, RI, USA
}

\begin{abstract}
As teachers' self-efficacy has been shown to be a crucial factor in technology integration, there is a need to understand the mechanisms that may raise teachers' self-efficacy toward technology integration. This article seeks to understand what sources of self-efficacy hands-on experiences with technology may provide to pre-service teachers. The participants were 37 students who were taking a course on digital literacies, where they composed a digital video in small groups. The data consists of students' individually written post-course self-evaluation reports. In the analysis of the reports, the authors identified text fragments that indicated either 1) sources of self-efficacy related to technology use, 2) students' willingness to use technology in their teaching, or 3) perceived value of technology use. Almost half of the students indicated some source of self-efficacy in their reports mastery experiences being the most frequent source of self-efficacy. The results suggest that digital video composition may be a good way to enhance students' self-efficacy related to technology use.
\end{abstract}

\section{KEYWORDS}

Digital Literacy, Multimodal Composition, Pre-Service Teacher, Teacher Education, Teacher's Self-Efficacy, Technology Integration

\section{INTRODUCTION}

Integrating technology in a pedagogically purposeful way in teaching is an important objective in pre- and in-service teacher education. However, research shows that pre-service teachers feel they are not well prepared to effectively use technology in the classroom (Drent \& Meelissen, 2008; Kay, 2006). This may explain why beginning teachers are limited in their technology use (Gao, Wong, Choy, \& Wu, 2011) or why they use technology to support traditional teaching instead of using it for creating learner-centered practices (Tondeur, Pareja Roblin, van Braak, Voogt, \& Prestridge, 2017). Furthermore, many teachers report a lack of confidence, limited technological competencies, and negative attitudes toward technology integration (Bingimlas, 2009). As teachers' self-efficacy has been shown to be one of the most crucial factors in technology integration (e.g., Chen, 2010; Wang, Ertmer, \& Newby, 2004), there is a need to understand the mechanisms that may raise teachers' self-efficacy toward technology integration. Hands-on experiences with engaging technologies may be one effective way to enhance pre-service teachers' confidence in using technology (Heo, 2009; Kiili, Kauppinen, Coiro \& Utriainen, 2016). This study seeks to understand what sources of selfefficacy hands-on experiences with technology may provide to pre-service teachers and students in an education administration program. 


\section{SELF-EFFICACY BELIEFS AND USE OF TECHNOLOGY IN TEACHING}

Self-efficacy is defined as a person's beliefs or confidence about his or her capability to accomplish a task under specific conditions (Bandura, 1997). Perceived self-efficacy beliefs affect individuals' initial choices of activities, the levels of the goals they set for themselves, the amount of effort they mobilize, and their outcome expectations (Bandura, 1997). Thus, it is one important factor explaining teachers' decisions about the use of technology in their classrooms-not only about whether to use technology (Chen, 2010; Teo, 2009) but about how to use technology and how much effort to put into implementing new technologies (cf. Tondeur et al., 2017). Self-efficacy beliefs are also related to getting through the barriers that people face in their activities (Zimmermann, 2000), which are also particularly significant when it comes to implementing new technologies in the classroom.

Several studies have reported instructional practices that have succeeded in enhancing pre-service teachers' self-efficacy toward technology integration (Banas \& York, 2014; Heo, 2009; Koh, 2011). In a study by Banas and York (2014), pre-service teachers engaged in authentic learning exercises where they designed four detailed technology-integrated lesson plans in small groups and gave one of the lessons as they would in a real classroom situation. Authentic learning exercises and feedback from instructors and peers seemed to have a positive influence on self-efficacy toward technology integration and intentions to use technology. In addition, Heo (2009) found that digital storytelling experiences improved pre-service teachers' self-efficacy toward technology integration. Further, technology-centered teaching experiences may increase pre-service teachers' self-efficacy toward technology integration (Han, Shin, \& Ko, 2017). Although studies suggest that the increase of selfefficacy beliefs is related to encouragement, the opportunity to experiment with technology, and feedback from reliable persons (cf. Tondeur al., 2017), there are fewer studies clarifying the sources of the increase in self-efficacy. This study seeks to understand the student experiences behind the increase in self-efficacy in technology use.

\section{THE SOURCES OF SELF-EFFICACY}

According to Bandura (1997), there are four basic information sources that inform self-efficacy beliefs: mastery experiences, vicarious experiences, verbal and social persuasion from others, and psychological and affective states. Mastery experiences are thought to have the strongest influence on self-efficacy, and they provide the most reliable evidence for one's judgments about one's own performance. Successful experiences usually increase one's confidence about performing well in similar tasks. Occasional failures should not affect one's self-efficacy beliefs, but repeated failures tend to weaken one's confidence (Bandura, 1997; Schunk \& Usher, 2011).

In addition to mastery experiences, vicarious experiences of observing others perform tasks can build one's efficacy beliefs. If others, especially similar others, can successfully accomplish the task, people are inclined to believe they will succeed at the task as well (Schunk \& Usher, 2011). Social models may be of particular importance in the development of self-efficacy when people are uncertain about their own abilities or have limited experience with the task at hand (Usher \& Pajares, 2008). In academic settings, it has been noted that observing peers' successful performance may sometimes promote students' self-efficacy more than observing teachers (Ritchie, 2016).

Verbal and social persuasion from others is the third source of self-efficacy (Bandura, 1997). Encouragement as well as evaluative positive feedback about performance may raise students' confidence and effort in accomplishing a task (Usher \& Pajares, 2008), whereas inconsiderately given negative feedback may erode student's self-efficacy. In order to be effective, social persuasions should be genuine (Britner \& Pajares, 2006) and come from someone respected and knowledgeable (Ritchie, 2016).

Finally, psychological and affective states also serve as a source of self-efficacy (Bandura, 1997), as strong emotional reactions to a task can provide cues to expected success or failure (Usher \& Pajares, 2008). Negative emotional reactions, such as nervousness or anxiety, may lower self-efficacy 
beliefs, whereas positive reactions, such as being in a good mood, may raise self-efficacy beliefs. In order to promote students' self-efficacy, educators should promote students' emotional well-being and try to reduce negative emotional states (Usher \& Pajares, 2008).

\section{PRESENT STUDY}

In the present study, self-efficacy toward the pedagogical use of technologies was supported among pre-service teachers and students in an education administration program through the utilization of digital video composition as a learning method in a course focused on digital literacies. This method was chosen because it is in line with recent curricula and standards that emphasize use of technology and digital literacy practices (Australian Curriculum, Assessment and Reporting Authority, n.d.; CCSS, 2010; The Finnish National Board of Education, 2014). Digital video composition is an emerging literacy practice that demands both the use of various technological tools and resources and the flexibility to move across different modes, genres, and discourses (Kress, 2003). In digital videos, students present meanings by combining multiple modes such as images, sounds, gestures, and textual elements (Miller, 2013).

The present study is based on our previous study (Kiili et al., 2016), which measured with quantitative methods whether experiences of digital video composition would have an impact on pre-service teachers' and adult educators' self-efficacy in three areas. These areas were computer self-efficacy (Compeau \& Higgins, 1995), teacher self-efficacy (Bandura, 1997; Ross, 1994), and self-efficacy toward technology integration (Andersson \& Maninger, 2007). The study showed that experiences with digital video composition enhanced pre-service teachers' and education students' computer self-efficacy. Among pre-service teachers, there was also a significant increase in their teacher self-efficacy and self-efficacy toward technology integration. Because these hands-on experiences proved to be quite an effective way to enhance pre-service teachers' confidence in using technology, there is a need to understand the sources behind the increase of confidence in technology use. At the end of the course, students wrote a self-evaluation report that were used to clarify how they reflected on perceived changes in their self-efficacy and their confidence and willingness to use technology in their teaching.

\section{METHODOLOGY}

\section{Participants}

Participants were 37 students who were taking a course on digital literacies at one Finnish university and volunteered to participate in the study. Of these students, 22 were enrolled in a teacher education program and 15 were enrolled in an education administration program. There were 25 females and 12 males ranging in age from 22 to 51 . All the participants were close to the end of their master's degree program. Participants were asked to describe their ability to compose digital videos before they took the course. In our sample, $31 \%$ indicated they could not compose videos at all, 39\% reported being minimally skilled at composing digital videos, and 30\% reported being moderately skilled (22\%) or very skilled (8\%) at composing digital videos. Each student was assigned an anonymized personal identification number (see Table 2 in Appendix A) that was used to refer to excerpts from students' self-evaluation reports.

\section{Course Design and Course Task}

The course consisted of six class meetings and 50 hours of independent work. The class meetings included four 90-minute interactive lectures related to teaching and learning with technology. The learning objectives shared with students were as follows: 1) build theoretical knowledge and methods for teaching in new digital learning environments and 2) compose a digital video to explore how the 
meanings can be created through different modalities. In addition to these explicitly stated learning objectives, the course also aimed to increase students' confidence in technology use and the integration of technology into their classroom practices.

The students' task was to compose a three-minute digital video in small groups of two to four students by using either Movie Maker or iMovie. Each group was asked to choose a teaching method or reform that concerned digital literacies, select a target audience, and convince that audience of the usefulness of the teaching method or need for the reform. The students were also asked to share some pedagogical implications in their video.

In order to support the students in a task that was new to many of them, the project was sequenced into manageable parts. The small groups prepared their videos in three phases and received feedback from instructors in each phase. In the first phase, the small groups wrote an idea paper about the topic and the target audience of their video. They were also asked to share their main arguments for the teaching method or reform selected. In second phase, the groups composed a short essay that included the theoretical background and an initial script for their video. In the third phase (fifth session), students began to develop their videos in small groups. During this session, the instructors (the first two authors) arranged a fifteen-minute individualized feedback session with each group. In these feedback sessions, the essays and initial scripts were discussed. After the fifth session, students had five weeks to produce their video.

In the final session, all the students watched, analyzed, and discussed each group's video. Thus, instead of just having teachers as an audience, the students had a wider audience from which they also got feedback on their final products. After the course, each student individually wrote a reflective self-evaluation report about his or her learning and group work.

Although students were given feedback during each phase of the task and one of lectures concerned multimodality in meaning-making, they did not get any explicit instruction on how to use the technologies needed in multimodal composition. Students were expected to explore and independently learn how to use these new technologies because they would face similar challenges in learning how to use new and constantly evolving technologies in their professional lives.

\section{Data Analyses}

Qualitative data sources included students' individually written end-of-course self-evaluation reports $(n=37)$. In these self-evaluation reports, students were asked to reflect on what they learned during the course and how they worked in small groups. Students were not asked to specifically comment on their confidence using technology; rather, the prompt was left more open-ended to see if students would spontaneously report any changes in their confidence levels.

While there were no length requirements for these self-evaluation reports, they varied considerably in length from one paragraph to three pages. First, phrases in students' self-evaluation reports that indicated either 1) a source of self-efficacy (i.e., one of Bandura's four sources of self-efficacy), 2) students' willingness to use technology in their teaching, or 3) perceived value of technology use, were identified. Table 1 shows the descriptions for each coding category. Initially, the inter-rater percent of agreement between the two researchers was $77 \%$. However, after the two coders met to resolve the coding discrepancies, their agreement increased to $100 \%$.

\section{RESULTS}

\section{Self-Reported Expressions Related to Self-Efficacy and Perceived Value of Technology}

In students' post-course self-evaluation reports $(\mathrm{n}=37), 12$ participants did not include any spontaneous expressions related to self-efficacy or perceptions of the value of technology use. Rather, the content of their reports focused more on specifying their learning and group work processes. 
Table 1. Analysis categories for the self-evaluation reports

\begin{tabular}{|l|l|}
\hline \multicolumn{1}{|c|}{ Category } & \multicolumn{1}{c|}{ Description } \\
\hline 1. Source of self-efficacy & Expression of confidence based on successful use of technology \\
\hline 1 a. Mastery experience & $\begin{array}{l}\text { Expression of confidence based on experience observing another's } \\
\text { successful use of technology }\end{array}$ \\
\hline 1 b. Vicarious experience & $\begin{array}{l}\text { Expression of confidence based on feedback received about their } \\
\text { use of technology }\end{array}$ \\
\hline 1c. Verbal and social persuasion from others & An emotional reaction that influenced their use of technology \\
\hline 1d. Psychological or affective state & $\begin{array}{l}\text { Expression of confidence or willingness to use technology in their } \\
\text { teaching or in work life in general in the future }\end{array}$ \\
\hline $\begin{array}{l}\text { 2. Confidence or willingness to use technology } \\
\text { in future }\end{array}$ & $\begin{array}{l}\text { Expression that shows that student sees perceived value in using } \\
\text { technology }\end{array}$ \\
\hline 3. Perceived value of technology & \multicolumn{2}{|c|}{} \\
\hline
\end{tabular}

From the 25 remaining reports, 47 spontaneous expressions were observed. From these expressions, 29 were coded as related to sources of self-efficacy, 9 as related to confidence or willingness to use technology in the future, and 9 as related to the perceived value of technology use. The number of expressions within each student's individual report ranged from 1 to 6, as shown in Appendix A. The pre-service teachers' self-evaluation reports contained more expressions related to self-efficacy or perceived value of technology use $(n=27)$ than the number of expressions in reports submitted by adult education students $(\mathrm{n}=20)$.

\section{Sources of Self-Efficacy}

Analysis of the students' end-of-course self-evaluations revealed 29 spontaneously expressed comments related to sources of self-efficacy. These comments were found in 19 of 37 reports (51\%), including 11 pre-service teachers and 8 adult education students. Among the 29 comments coded as sources of self-efficacy, only two types of Bandura's four sources of self-efficacy were observed: mastery experiences and vicarious experiences. Next, some illustrative examples of the kinds of comments that students made are offered with interpretations of how these align with two of Bandura's sources of self-efficacy.

The students' self-evaluation reports included 25 comments related to mastery experiences. In these comments, students typically expressed their success with digital video composition in general ways (e.g., "It was great to realize that with only a short introduction, I can create a pretty nice video" [student 11]), or they expressed their mastery of a particular program (e.g., "In particular, I was delighted that I learned to use Movie Maker in the course, because I hadn't ever used it before" [student 9]).

There were many students who, before the course, had not had any experience with digital video composition. Two of these students said that their successful experiences during the course would give them confidence in other new and unfamiliar situations (e.g., "From these course experiences, I feel that I have gotten the courage to try new things. I can now be open to the unknown" [student 28]). This is an important attitude for future educators to have because new kinds of technologies are constantly appearing and teachers will often need the courage to try new things by themselves without formal instruction. Further, for one participant, positive experiences in the current course helped change her perception of herself as a technology user: "I have always regarded myself as a very clumsy person when it comes to any kind of technology use. However, this spring has shown me that maybe I am not as bad as I believed I am" [student 36]. 
Across the sample of self-evaluation reports, students spontaneously reported only four vicarious experiences. In three of these comments, students' observations of the successful behavior of their peers made them believe that they also would succeed at the same kind of task by themselves. A preservice teacher described her experiences as follows: "I didn't edit the video with my own hand, but I watched all the steps taken by the team member with sophisticated technical skills. I'm confident that I would have been able to do the same by myself" [student 4]. One vicarious experience reported by a pre-service teacher was related to observing the pedagogies of the course instructors: "Activities used in the course were also something that I 'learned.' For the first time in my university studies, I saw a very functional course design that did not feel disjointed. It was also nice to see that university studies can provide versatile learning methods. Why couldn't this also happen in primary school (grades 1 to 6 in Finland)?" [student 23].

\section{Confidence or Willingness to Use Technology in Prospective Teaching}

Eight (22\%) of the 37 students spontaneously expressed in their end-of-course self-evaluation reports that they are now confident or willing to use technology in their teaching. Among these eight students, five were pre-service teachers and three were adult education students. Among the nine expressions of confidence collected from these eight post-course evaluation reports, four responses were related to technology use in general (e.g., "The course gave me ideas and the courage to try to use different kinds of digital learning environments in my teaching" [student 4]) and five responses were related to applying a specific digital learning environment in their teaching (e.g., "I got excited about digital storytelling. As a future student counselor, I could ask students to compose digital stories about different professions" [student 27]).

\section{Perceived Value of Technology}

The self-evaluation reports included nine spontaneous expressions related to the perceived value of technology use. Six of these expressions came from adult education students' reports and three were from pre-service teachers' reports. In their comments, students acknowledged the value of digital technologies for learning, communication, and teaching. For instance, one student described her realization of how multimodal texts can mediate learning: "I learned that texts can be produced not only by writing but also with other modes. One can also learn from multimodal texts, sometimes even more than from written ones" [student 18]. Another student discussed the benefits of multimodal communication: "I learned a lot about multimodal means of communication. I learned that one can communicate ideas and feelings with a video in a way that cannot necessarily be mediated with written texts. There are many different ways to use video for persuasion." [student 30].

\section{DISCUSSION}

This study sought to clarify what kinds of sources may explain the increase of technology-related self-efficacy after hands-on experiences with technology that has been reported elsewhere (Kiili et al., 2016). The self-evaluation reports written after the course revealed that the increases in the students' self-efficacy can be probably explained by the mastery experiences and vicarious experiences that students engaged in during the course. Almost half of the students indicated some source of self-efficacy in their self-evaluation reports, even though they were not prompted to consider issues related to self-efficacy.

Mastery experiences were much more often reported as sources of self-efficacy than vicarious experiences. Two other sources of self-efficacy, verbal and social persuasion of others and psychological or affective state, were not observed in the self-reported data collected from the participants. This finding is in line with Banduras' (1997) notion that mastery experiences are the most important source for self-efficacy. In this study, mastery experiences may also have been especially powerful because the digital video composition task provided the sense of ownership of a concrete, 
digitally created product (cf. Ritchie, 2016). This highlights the responsibility of educators to provide students with opportunities in which they can experience success even with technologies and digital practices that are new to them.

However, it is good to keep in mind that other sources of self-efficacy may play a larger role early in learning and that mastery experiences may be crucial later in learning when people have gained more experience with similar kinds of tasks (Tschannen-Moran, Hoy, \& Hoy, 1998). Thus, even though students reported very few vicarious experiences, they might have been particularly important for some students. Emotionally, it is easier to start as an observer and move toward a more active role with technology. For less-experienced technology users, vicarious experiences may also offer an opportunity to learn effective strategies for managing task demands when implementing new technologies (cf. Tschannen-Moran \& McMaster, 2009). In addition, working with a small group may also provide opportunities for vicarious experiences wherein observers can easily identify with models who are their peers (Bandura, 1997). Finally, although the self-evaluation reports included only one vicarious experience that was related to observing the teachers in the course, educators' roles in using technology can be regarded as an important motivator for technology integration in the classroom (cf. Tondeur et al., 2012).

It might be that if students had been prompted to explain the changes in their perceived selfefficacy, a more detailed understanding of the possible explanations for the increase in students' perceived self-efficacy would have been obtained. On the other hand, when prompted, students may generate answers that they think that they are expected to provide (Hinkin, 1998). In this study, students' expressions of self-efficacy can be regarded as genuine. In future work, students with the biggest changes in perceived self-efficacy could be interviewed and invited to elaborate on their experiences and the sources of their development (cf. Usher \& Pajares, 2008).

Further prompting might have also elicited a better understanding of what role verbal persuasion from others and psychological or affective states might have played in the increase in self-efficacy. Because feedback at the right time is likely to promote self-efficacy (Ritchie 2016), more precise prompts could have revealed what role the several face-to-face feedback situations played. However, it is probable that access to students' affective states would have required interviews or self-reporting in the different phases of the digital video production process. Even without this, a supportive working culture was observed in the groups, which was also reflected in many self-evaluation reports. This working culture was far removed from one of competition and harmful comparison (cf. Usher \& Pajares, 2008).

Even without being prompted, about one-fifth of the students reported an intention to use technology in their prospective teaching. Appendix A shows that six out of eight of these students reported both sources of self-efficacy and intention to use technology. Previous studies (e.g., Anderson, Groulx, \& Maninger, 2011; Banas \& York, 2014; Chen, 2010) have shown the link between perceived self-efficacy and the use of or intention to use technology. Thus, the students who reported mastery or vicarious experiences may also be inclined to use technology in their teaching. Also about one-fifth of the students reported perceiving the value of technology. This is in line with the previous study that found that training in student-centered technology has an effect on how pre-service teachers value technology in teaching and learning (Chen, 2010).

There are several limitations in this study. First, because of the small sample size and the presence of two unique populations in the sample, the results must be interpreted with some caution. Second, the course was voluntary, so it might have attracted certain types of students. For example, in this course male students were overrepresented in comparison to other literacy-related courses in the teacher education program. Third, this study did not include a control group that was taught the same content with more traditional study methods.

Nevertheless, the strength of this study is that it was based on our earlier quantitative study's finding of a significant increase in pre-service teachers' self-efficacy in using technologies. The qualitative methods (Creswell, 2014) used in the present study helped illuminate at least a partial 
explanation of the increase of self-efficacy. This is an important contribution to a field that has mainly investigated self-efficacy quantitatively (Usher \& Pajares, 2008). Further, qualitative findings also confirmed, at least partly, the results of the quantitative approach. These two layers of evidence support the conclusion that providing well-planned hands-on digital video composition experiences helps pre-service teachers to develop confidence in using technology and sharing ideas through multimedia formats. Connecting this type of course with a practicum where pre-service teachers could apply their learning experiences in authentic ways with real students could strengthen students' confidence even further (see also Banas \& York, 2014; Tondeur et al., 2017). 


\section{REFERENCES}

Anderson, S. E., \& Maninger, R. M. (2007). Preservice teachers' abilities, beliefs, and intentions regarding technology integration. Journal of Educational Computing Research, 37(2), 151-172. doi:10.2190/H1M8562W-18J1-634P

Australian Curriculum, Assessment and Reporting Authority. (n.d.) F-10 Curriculum. Retrieved from http:// www.australiancurriculum.edu.au/Curriculum/Overview

Banas, J. R., \& York, C. S. (2014). Authentic learning exercises as a means to influence preservice teachers' technology integration self-efficacy and intentions to integrate technology. Australasian Journal of Educational Technology, 30(6), 728-746. doi:10.14742/ajet.362

Bandura, A. (1997). Self-efficacy: The exercise of control. New York, NY: Freeman.

Bingimlas, K. A. (2009). Barriers to the successful integration of ICT in teaching and learning environments: A review of the literature. Eurasia Journal of Mathematics, Science \& Technology Education, 5(3), 235-245.

Chen, R. (2010). Investigating models for preservice teachers' use of technology to support student-centered learning. Computers \& Education, 55(1), 32-42. doi:10.1016/j.compedu.2009.11.015

Compeau, D. R., \& Higgins, C. A. (1995). Computer self-efficacy: Development of a measure and initial test. Management Information Systems Quarterly, 19(2), 189-211. doi:10.2307/249688

Creswell, J. W. (2014). Research design: Qualitative, Quantitative and mixed methods approaches (4th ed.). London: Sage.

Drent, M., \& Meelissen, M. (2008). Which factors obstruct or stimulate teacher educators to use ICT innovatively? Computers \& Education, 51(1), 187-199. doi:10.1016/j.compedu.2007.05.001

Gao, P., Wong, A. F., Choy, D., \& Wu, J. (2011). Beginning teachers' understanding performances of technology integration. Asia Pacific Journal of Education, 31(2), 211-223. doi:10.1080/02188791.2011.567003

Han, I., Shin, W. S., \& Ko, Y. (2017). The effect of student teaching experience and teacher beliefs on pre-service teachers' self-efficacy and intention to use technology in teaching. Teachers and Teaching, 23(7), 829-842; Advanced online publication. doi:10.1080/13540602.2017.1322057

Heo, M. (2009). Digital Storytelling: An empirical study of the impact of digital storytelling on pre-service teachers' self-efficacy and dispositions towards educational technology. Journal of Educational Multimedia and Hypermedia, 18(4), 405-428.

Hinkin, T. R. (1998). A brief tutorial on the development of measures for use in survey questionnaires. Organizational Research Methods, 1(1), 104-121. doi:10.1177/109442819800100106

Kay, R. H. (2006). Evaluating strategies used to incorporate technology into pre- service education: A review of the literature. Journal of Research on Technology in Education, 38, 383-408. doi:10.1080/15391523.2006 .10782466

Kiili, C., Kauppinen, M., Coiro, J., \& Utriainen, J. (2016). Measuring and supporting pre-service teachers' self-efficacy towards computers, teaching, and technology integration. Journal of Technology and Teacher Education, 24(4), 443-469.

Koh, J. H. L. (2011). Computer skills instruction for pre-service teachers: A comparison of three instructional approaches. Computers in Human Behavior, 27(6), 2392-2400. doi:10.1016/j.chb.2011.08.002

Kress, G. (2003). Literacy in the new media age. London: Routledge. doi:10.4324/9780203164754

Miller, S. M. (2013). A research metasynthesis on digital video composing in classrooms: An evidencebased framework toward a pedagogy for embodied learning. Journal of Literacy Research, 45(4), 386-430. doi:10.1177/1086296X13504867

Ritchie, L. (2016). Fostering self-efficacy in higher education students. London: Palgrave. doi:10.1007/978-1137-46378-4 
Ross, J. A. (1994). The impact of an inservice to promote cooperative learning on the stability of teacher efficacy. Teaching and Teacher Education, 10(4), 381-394. doi:10.1016/0742-051X(94)90020-5

Schunk, D., \& Usher, E. (2011). Assessing self-efficacy for self-regulated learning. In B. J. \& D. Schunk (Eds.), Handbook of self-regulation of learning and performance (pp. 282-297). New York, NY: Taylor \& Francis.

Teo, T. (2009). Modeling technology acceptance in education: A study of pre-service teachers. Computers \& Education, 52(2), 302-312. doi:10.1016/j.compedu.2008.08.006

The Finnish National Board of Education. (2014). Finnish National curriculum for basic education. Retrieved from http://www.oph.fi/english/curricula_and_qualifications/basic_education

Tondeur, J., Roblin, N. P., van Braak, J., Voogt, J., \& Prestridge, S. (2017). Preparing beginning teachers for technology integration in education: Ready for take-off? Technology, Pedagogy and Education, 26(2), 157-177. doi:10.1080/1475939X.2016.1193556

Tondeur, J., van Braak, J., Sang, G., Voogt, J., Fisser, P., \& Ottenbreit-Leftwich, A. (2012). Preparing pre-service teachers to integrate technology in education: A synthesis of qualitative evidence. Computers \& Education, 59(1), 134-144. doi:10.1016/j.compedu.2011.10.009

Tschannen-Moran, M., Hoy, A. W., \& Hoy, W. K. (1998). Teacher efficacy: Its meaning and measure. Review of Educational Research, 68(2), 202-248. doi:10.3102/00346543068002202

Tschannen-Moran, M., \& McMaster, P. (2009). Sources of self-efficacy: Four professional development formats and their relationship to self-efficacy and implementation of a new teaching strategy. The Elementary School Journal, 110(2), 228-245. doi:10.1086/605771

Usher, E. L., \& Pajares, F. (2008). Sources of self-efficacy in school: Critical review of the literature and future directions. Review of Educational Research, 78(4), 751-796. doi:10.3102/0034654308321456

Wang, L., Ertmer, P. A., \& Newby, T. J. (2004). Increasing preservice teachers' self-efficacy beliefs for technology integration. Journal of Research on Technology in Education, 36(3), 231-250. doi:10.1080/15391523.2004.1 0782414

Zimmerman, B. J. (2000). Self-efficacy: An essential motive to learn. Contemporary Educational Psychology, 25(1), 82-91. doi:10.1006/ceps.1999.1016 PMID:10620383 


\section{APPENDIX A}

Table 2. Number of expressions related to self-efficacy or perceived value of technology in each students' self-evaluation report

\begin{tabular}{|c|c|c|c|c|c|}
\hline Student & $\begin{array}{c}\text { Mastery } \\
\text { experience }\end{array}$ & $\begin{array}{c}\text { Vicarious } \\
\text { experience }\end{array}$ & $\begin{array}{c}\text { Confidence or } \\
\text { willingness to use } \\
\text { technology }\end{array}$ & $\begin{array}{l}\text { Perceived value } \\
\text { of technology }\end{array}$ & Total \\
\hline 1 & 1 & - & - & - & 1 \\
\hline 2 & 1 & - & - & - & 1 \\
\hline 3 & - & - & - & - & - \\
\hline 4 & 3 & 1 & 2 & - & 6 \\
\hline 5 & - & - & - & - & - \\
\hline 6 & 1 & - & - & - & 1 \\
\hline 7 & 3 & - & 1 & - & 4 \\
\hline 8 & - & - & - & - & - \\
\hline 9 & 1 & - & - & 1 & 2 \\
\hline 10 & 1 & - & - & - & 1 \\
\hline 11 & 2 & 1 & - & - & 3 \\
\hline 12 & - & - & - & 1 & 1 \\
\hline 13 & - & - & - & - & - \\
\hline 14 & 1 & - & - & 2 & 3 \\
\hline 15 & 1 & - & - & - & 1 \\
\hline 16 & 2 & - & - & - & 2 \\
\hline 17 & 2 & - & - & - & 2 \\
\hline 18 & - & - & - & 1 & 1 \\
\hline 19 & - & - & - & - & - \\
\hline 20 & - & - & - & 1 & 1 \\
\hline 21 & - & - & - & - & - \\
\hline 22 & - & - & - & - & - \\
\hline 23 & 1 & 1 & - & - & 2 \\
\hline 24 & - & - & - & - & - \\
\hline 25 & - & - & - & - & - \\
\hline 26 & 1 & - & - & - & 1 \\
\hline 27 & 1 & - & 1 & 1 & 3 \\
\hline 28 & - & - & 1 & - & 1 \\
\hline 29 & - & - & - & 1 & 1 \\
\hline 30 & 1 & - & - & 1 & 2 \\
\hline 31 & 1 & - & 1 & - & 2 \\
\hline 32 & - & - & 1 & - & 1 \\
\hline 33 & - & - & - & - & - \\
\hline 34 & - & - & - & - & - \\
\hline 35 & - & - & - & - & - \\
\hline 36 & 1 & - & 1 & - & 2 \\
\hline 37 & - & 1 & 1 & - & 2 \\
\hline Total & 25 & 4 & 9 & 9 & 47 \\
\hline
\end{tabular}


Merja Kauppinen received her PhD in the Centre of Applied Linguistics in the University of Jyväskylä, Finland, in 2010. Since 2009 she has been working on the Department of Teacher Education in the University of Jyväskylä. She is a lecturer of mother tongue (Finnish) and literature for pre- and in-service teachers and instructs both classroom teachers and subject teachers. Her main interest areas are reading and writing literacy and their instruction, academic reading and writing skills, interdisciplinary learning, and migrants' L1. She has taken part in the renewing process of the latest Finnish national core curriculum 2014 and cooperates widely with schools.

Carita Kiili is a post-doctoral fellow at the Department of Education, University of Oslo, Norway. She received her PhD in Education 2012 from the University of Jyväskylä, Finland. Her research interests lie on digital literacies including online reading and multimodal composition.

Julie Coiro is an associate professor in the School of Education at the University of Rhode Island. She teaches undergraduate and graduate courses in reading and co-directs the Graduate Certificate in Digital Literacy and the $\mathrm{PhD}$ in Education program. 